\title{
Molecular Dynamics Simulations of Cetyltrimethylammonium Bromide (CTAB) Micelles and their Interactions with a Gold Surface in Aqueous Solution
}

\author{
José Adriano da Silva, ${ }^{a}$ Roberta P. Dias, ${ }^{b}$ Gabriel C. A. da Hora,${ }^{b}$ Thereza A. Soares ${ }^{*, b}$ \\ and Mario R. Meneghetti $*$,
}

${ }^{a}$ Grupo de Catálise e Reatividade Química (GCaR), Instituto de Química e Biotecnologia,
Universidade Federal de Alagoas, Av. Lourival de Melo Mota, s/n, 57072-970 Maceió-AL, Brazil

${ }^{b}$ Grupo de Modelagem de Biomateriais (BioMat), Departamento de Química Fundamental, Universidade Federal de Pernambuco, Cidade Universitária, 50740-560 Recife-PE, Brazil

\begin{abstract}
Surfactants are molecular structures with remarkable physicochemical properties and applications. Most of their characteristics are due to their ability to promote aggregation and interactions with different interfaces. The scarcity of theoretical studies dedicated to evaluating the forces involved in these interactions prompted us to propose other models capable of reproducing the experimental data in better ways. We carried out molecular dynamics (MD) simulations to obtain a model for cetyltrimethylammonium bromide (CTAB), selected from gromos54a7 force field parameters, that better describes most of its behaviors in aqueous solution (micellar structure, counterion dissociation, etc.) and its adsorption pattern on a gold surface. The parameters adopted for one of the models were able to mimic several characteristics suggested by experimental measurements of the CTAB micelles, as well their adsorption pattern on a gold surface. Indeed, this model was able to obtain quasi-spherical micelles, as well as a pattern of adjacent cylindrical micelles with alkyl chain interactions on a gold surface.
\end{abstract}

Keywords: molecular dynamics, micelles, interface interaction, cetyltrimethylammonium bromide, gold

\section{Introduction}

Surfactants are a class of compounds containing a polar group, charged or neutral, attached to a long hydrophobic tail. ${ }^{1,2}$ These are remarkably versatile compounds with a broad variety of important applications in the pharmaceutical, medical, and food industries and for nanomaterial synthesis. ${ }^{3,4}$ Above a certain temperature in solution (the Krafft temperature), surfactants tend to aggregate to minimize unfavorable interactions between the surfactants and the surrounding environment. ${ }^{5}$ The minimum concentration required for surfactant aggregation is defined as the critical micellar concentration (CMC), and most of the characteristics of these aggregates are controlled by factors such as the solvent type, chemical structure of the surfactant, and solution conditions (e.g., concentration, temperature, presence of additives, and ionic strength). ${ }^{6}$ Variations of these factors yield aggregates with different

*e-mail: thereza.soares@ufpe.br; mrm@qui.ufal.br morphologies such as spherical or ellipsoidal micelles, cylindrical or thread-like micelles, disk-like micelle, membranes and vesicles. ${ }^{7}$ These self-assembled structures have been characterized by a number of techniques, such as dynamic light scattering (DLS) ${ }^{8}$ nuclear magnetic resonance (NMR), ${ }^{9,10}$ fluorescence spectroscopy, ${ }^{11}$ quasielastic neutron scattering (QENS), ${ }^{12,13}$ small-angle X-ray scattering (SAXS), ${ }^{14,15}$ and small-angle neutron scattering (SANS). ${ }^{16,17}$ Computational simulations have also been employed to explore the structures and dynamical behaviors of micelles for different surfactants. ${ }^{18}$

Considering that no holes exist within a micelle, its radius is estimated as the maximum extension of a hydrocarbon chain and can be evaluated by using the following equation:

$1_{\max }=0.15+0.1265 n_{C}$

where $l_{\max }$ is the maximum length in $n m$ and $n_{C}$ is the number of carbon atoms in the chain. ${ }^{19}$ Indeed, under the previously mentioned conditions, $1_{\max }$ plus the length of 
the polar group is approximately equal to the radius of the spherical micelles. ${ }^{20}$

Particularly, we are interested in studying the surfactant cetyltrimethylammonium bromide, $\left[\mathrm{CH}_{3}\left(\mathrm{CH}_{2}\right)_{15} \mathrm{~N}^{+}\left(\mathrm{CH}_{3}\right)_{3}\right] \mathrm{Br}^{-}$ (CTAB), which is a well-known example of a cationic surfactant. CTAB exhibits antibacterial properties, ${ }^{21}$ has applications in DNA extraction, and is widely used in the synthesis of metallic nanoparticles as a stabilizer and growth-driving agent of nanoparticles. ${ }^{22,23}$ Its $1^{\text {st }}$ and $2^{\text {nd }} \mathrm{CMCs}$ in water are $0.92 \mathrm{mM}^{24}$ and $0.27 \mathrm{M},{ }^{25}$ respectively, and its Krafft temperature is $298 \mathrm{~K} .{ }^{26}$ As expected, the counterions (bromide) are located near the external positively charged border of the $\mathrm{CTA}^{+}$aggregates; however, it is important to mention that many assembly properties, such as the morphology, size, charge, and intra-micellar interactions, depend on the nature of the counterion. ${ }^{27,28}$ This is particularly evident if one compares the structural properties of CTAB and CTAC, $\left[\mathrm{CH}_{3}\left(\mathrm{CH}_{2}\right)_{15} \mathrm{~N}^{+}\left(\mathrm{CH}_{3}\right)_{3}\right] \mathrm{Cl}^{-}$. They differ in many aspects of the micellar behavior; for example, CTAC shows no spherical-cylindrical transition in its micelles, even at high concentrations of CTAC. ${ }^{29}$

Despite the large number of experimental studies and large amount of data on most of the proprieties of CTAB already at our disposal, few theoretical studies have been dedicated to evaluating and modeling some important characteristics of CTAB micelles. Cata et al. ${ }^{30}$ carried out already MD simulations for CTAB in aqueous solutions considering different micelle sizes. However, these simulations were carried out under relatively short simulation time (10.5 ns), that can compromise in some aspects the results. Meena and Sulpizi ${ }^{31}$ developed an elegant work in which created a system for MD simulation of CTAB micelles (aggregation number 90 and time simulation $200 \mathrm{~ns}$ ), nevertheless they did not present any explanation for the selection of the CTAB parameters adopted in their work. Thus, due to this lack of information and limitations prompted us to carry out other MD simulations for CTAB micelles, comparing different bromide anions parameters already available in literature, and face the results with physical-chemical properties of $\mathrm{CTAB}$ micelles in aqueous solutions for model validation. Furthermore, we also present some aspects of CTAB micelles adsorption pattern on a gold surface.

\section{Methodology}

\section{System setup}

Five MD simulations were performed: one CTAC system, three $\mathrm{CTAB}$ systems, and one $\mathrm{CTAB} / \mathrm{Au}$ system, which are denoted as $\mathrm{CTAC} \mathrm{CTAB}_{\mathrm{H}}, \mathrm{CTAB}_{\mathrm{N}}, \mathrm{CTAB}_{\mathrm{R}}$ and $\mathrm{CTAB}_{\mathrm{R}} / \mathrm{Au}$.
The topology and atomic parameters for the $\mathrm{CTA}^{+}$units were adapted from the dipalmitoylphosphatidylcholine lipid in the GROMOS parameter set gromos54a7 (for more details, see Supplementary Information, Figure S1). ${ }^{32}$ The Wang and Larson charges were applied to the polar group: the nitrogen atom was assigned $0 e$ charge and the amino group $+0.25 e$ charge. ${ }^{33}$ The atom labels and the charge distributions of the $\mathrm{CTA}^{+}$unit are described in the Supplementary Information (Figure S2). The chloride Lennard-Jones atomic parameter (LJAP) was taken from the GROMOS parameter set gromos54a7..$^{32}$ The bromide LJAPs adopted for evaluation were those proposed by Hasse and co-workers ${ }^{34}\left(\mathrm{~B}_{\mathrm{H}}\right)$, Netz and co-workers ${ }^{35}\left(\mathrm{~B}_{\mathrm{N}}\right)$, and Reiser et al..$^{36}\left(\mathrm{~B}_{\mathrm{R}}\right)$. Finally, the LJAP employed for gold was that developed by Heinz et al. ${ }^{37}$ and was already used in previous studies. ${ }^{31,38}$ All LJAPs adopted in this work are summarized in Table 1. For the micelle systems, the number of surfactant units used in the simulations was chosen based on the available experimental data $^{27,28,39,40}$ and previous theoretical studies. ${ }^{30,31,38-40}$ Thus, the input configuration of the system was constructed, like in other former studies, as a bilayer of 90 surfactant units and a suitable number of water molecules for each system, ca. 4980 (see Figure 1 and Table 1). ${ }^{30,31,38-40}$ For the CTAB/Au system, the gold surface, with a (100) facet arrangement, was constructed using 1600 atoms, employing the protocol described by Meena and Sulpizi. ${ }^{31}$ Two CTA ${ }^{+}$bilayers, having 90 fragments each, were added to the (100) gold surface (Figure 2). A total of $180 \mathrm{~B}_{\mathrm{R}}$ bromides were added as counterions to neutralize the charged polar groups of the bilayers, and 4766 water molecules were added (see Figure 2 and Table 1).

\section{Simulation procedures}

The initial configurations were individually hydrated and submitted to an energy-minimization procedure for 5000 steps of steepest descent. The simple point charge (SPC) water model was used for all simulations. ${ }^{41}$ The systems were simulated under isothermal-isobaric NPT conditions, and periodic boundary conditions were applied to the boxes (cubic for the bilayers and rectangular for the simulation with the gold surface) in all directions. During the equilibration and production phases, the leap-frog algorithm was used to integrate Newton's equations of motion with a time step of 0.002 ps. Each simulation trajectory was $200 \mathrm{~ns}$ long. The center-of-mass motion was removed every 5 steps. The Berendsen thermostat was used to sustain the systems at a temperature of $300 \mathrm{~K}$ via an independent coupling of the temperatures of the solute and solvent with a time constant of 0.4 ps. ${ }^{42}$ The pressure 
Table 1. Simulated systems and Lennard-Jones atomic parameters used for bromide and chloride ions and gold atoms

\begin{tabular}{|c|c|c|c|c|c|c|c|}
\hline \multirow{2}{*}{ System } & \multirow{2}{*}{$\begin{array}{l}\text { Surfactant } \\
\text { units }\end{array}$} & \multirow{2}{*}{$\begin{array}{c}\text { Solvent } \\
\text { molecules }\end{array}$} & \multirow{2}{*}{$\begin{array}{l}\text { Aggregation } \\
\text { mode }\end{array}$} & \multicolumn{2}{|c|}{ LJAP-12,6/ $\left(\mathrm{kJ} \mathrm{mol}^{-1} \mathrm{~nm}^{6}\right)$} & \multicolumn{2}{|c|}{ LJAP- $\sigma, \varepsilon$} \\
\hline & & & & $\mathrm{C}_{12} \times 10^{-05}$ & $\mathrm{C}_{6} \times 10^{-02}$ & $\sigma / \AA$ & $\varepsilon / \mathrm{k}_{\mathrm{B}} / \mathrm{K}$ \\
\hline CTAC & 90 & 4974 & micelle & 10.69156 & 1.380625 & 3.47 & 217.37 \\
\hline $\mathrm{CTAB}_{\mathrm{H}}$ & 90 & 4985 & micelle & 6.5480464 & 2.765569 & 4.54 & 100.00 \\
\hline $\mathrm{CTAB}_{\mathrm{N}}$ & 90 & 4988 & micelle & 2.5736 & 0.731899 & 3.89 & 62.54 \\
\hline $\mathrm{CTAB}_{\mathrm{R}}$ & 90 & 4983 & micelle & 5.10031 & 5.8243749 & 4.54 & 200.00 \\
\hline $\mathrm{CTAB} / \mathrm{Au}$ & 180 & 4766 & layer & 0.964326 & 2.92057 & 2.95 & 2671.71 \\
\hline
\end{tabular}

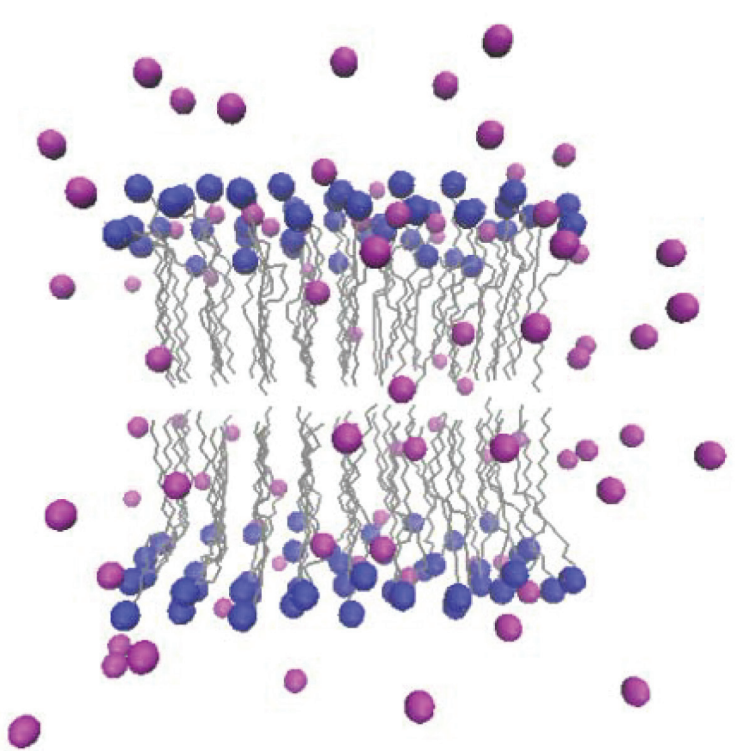

Figure 1. Initial setup of the surfactant bilayer arrangement. The magenta spheres represent the anions, and the gray lines and blue spheres represent the apolar and polar regions, respectively, of the $\mathrm{CTA}^{+}$moiety. The water molecules were omitted for clarity.

was maintained by the Parrinello-Rahman barostat by subjecting a weak coupling of particle coordinates and box dimensions in all directions to a pressure bath at $1.0 \mathrm{bar}^{43}$ Anisotropic coordinate scaling was used with a relaxation time of 0.4 ps and a compressibility of $4.5 \times 10^{-5} \mathrm{bar}^{-1}$, which is appropriate for water. No bond constraints were applied during the simulations. A generalized reaction-field correction and a cutoff of $1.4 \mathrm{~nm}$ were used for both van der Waals and long-range electrostatic interactions with a permittivity (dielectric constant) of $66 .{ }^{44}$ In all simulations, the pair lists for short-range nonbonded and long-range electrostatic interactions were updated every five time steps. The configurations of the trajectory were recorded every $1 \mathrm{ps}$.

The MD-derived properties that we analyzed include the root-mean-square deviation (RMSD), partial density number of $\mathrm{CTA}^{+}$functional groups, time-dependent distributions of water and bromide groups, and dissociation degree. GROMACS 4.5.5 was used for all MD simulations

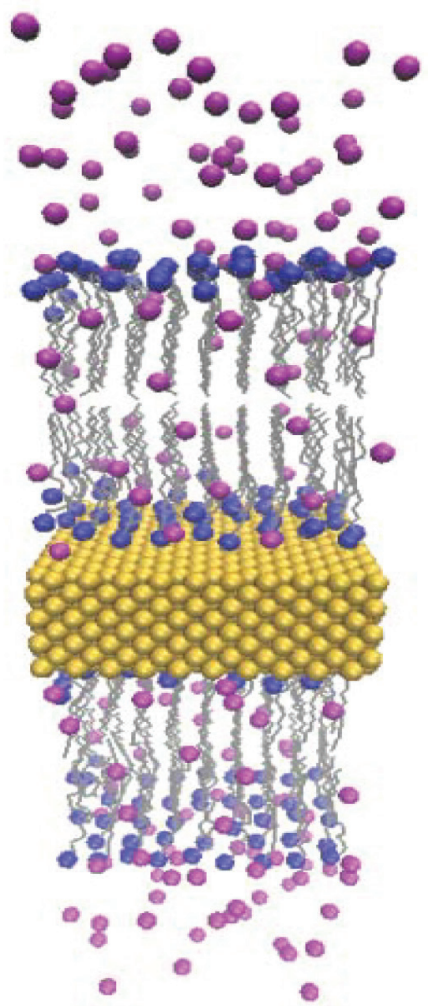

Figure 2. Initial setup of surfactant bilayer arrangement on the gold surface (yellow atoms). The magenta spheres represent the bromide ions $\left(\mathrm{B}_{\mathrm{R}}\right)$, and the gray lines and blue spheres represent the apolar and polar regions, respectively, of the $\mathrm{CTA}^{+}$moiety. The water molecules were omitted for clarity.

and trajectory analyses. ${ }^{45}$ The software VMD version 1.9.1 was used for trajectory visualization and preparation of the figures. ${ }^{46}$

\section{Results and Discussion}

As already mentioned above, we chose to model a system containing 90 units of CTAB dispersed in water that could evolve to form spherical micelles. Indeed, 90 is the expected agglomeration number $\left(\mathrm{N}_{\mathrm{agg}}\right)$ for spherical CTAB micelles when the CTAB concentration is just above the $1^{\text {st }} \mathrm{CMC} \cdot{ }^{47}$ Nevertheless, it is worth mentioning that the ration between $\mathrm{CTA}^{+}$fragments and the amount 
of water molecules adopted for each simulation represents a system well above the $1^{\text {st }} \mathrm{CMC}$. But this compaction is desirable to reduce the computational cost. Furthermore, this input allows us to compare our results with previous MD studies..$^{30,31,38-40,48}$

\section{Sufficiency of time simulation}

From the root-mean-square deviation (RMSD) plot (Figure 3), one can verify that in the simulations for CTAC, $\mathrm{CTAB}_{\mathrm{H}}$ and $\mathrm{CTAB}_{\mathrm{R}}$, the conformations stabilize at approximately $30 \mathrm{~ns}$ and remain stable for the rest of the simulation, which lasts $200 \mathrm{~ns}$. However, the $\mathrm{CTAB}_{\mathrm{N}}$ model only achieves structural stability after $50 \mathrm{~ns}$. Indeed, this longer time is, in fact, mostly due to the incapacity of the system to achieve a suitable micellar structure. Further details are discussed below.
The micellar radius and counterion dissociation degree

To determine the average radius of the simulated micelles, as well as the counterion dissociation degree, we measured the radial density distributions of $\mathrm{N}$ and $\mathrm{Br}$ elements in the simulated micelles. In general, the average radius of the micelles can be estimated by measuring the distance from the center to the border of the micelle, where the density of the $\mathrm{N}$ or $\mathrm{Br}$ elements is maximum. Thus, for the last $50 \mathrm{~ns}$, the radial distributions of the simulated micelles in water are presented in Figures 4 to 7 and summarized in Table 2.

The simulations for $\mathrm{CTAB}_{\mathrm{H}}, \mathrm{CTAB}_{\mathrm{R}}$, and CTAC obtained the expected micellar shape for the conditions adopted in the simulations (i.e., a spherical shape for an $\mathrm{N}_{\text {agg }}$ of 90); however, the $\mathrm{CTAB}_{\mathrm{N}}$ micelle model did not. Indeed, the initially adopted structure did not evolve far

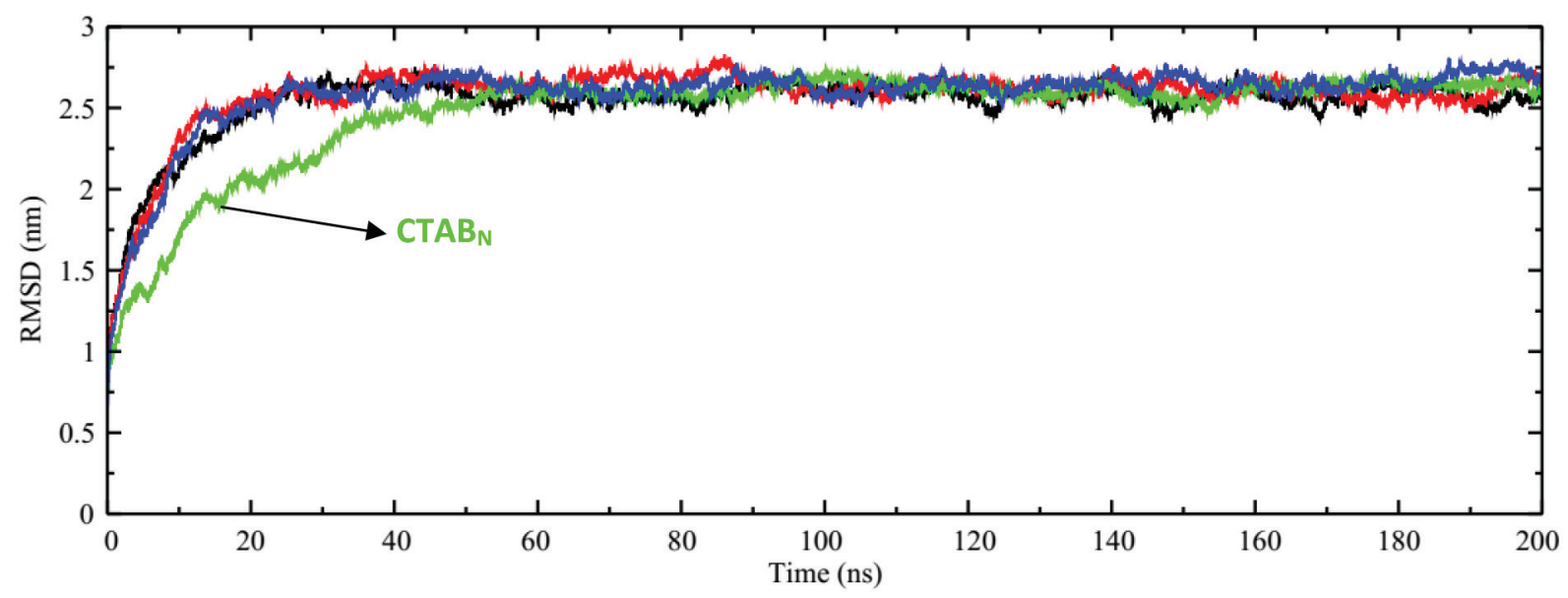

Figure 3. RMSD plot for micelle simulations. The CTAC is shown in black, $\mathrm{CTAB}_{H}$ in red, $\mathrm{CTAB}_{\mathrm{N}}$ in green, and $\mathrm{CTAB}_{\mathrm{R}}$ in blue.

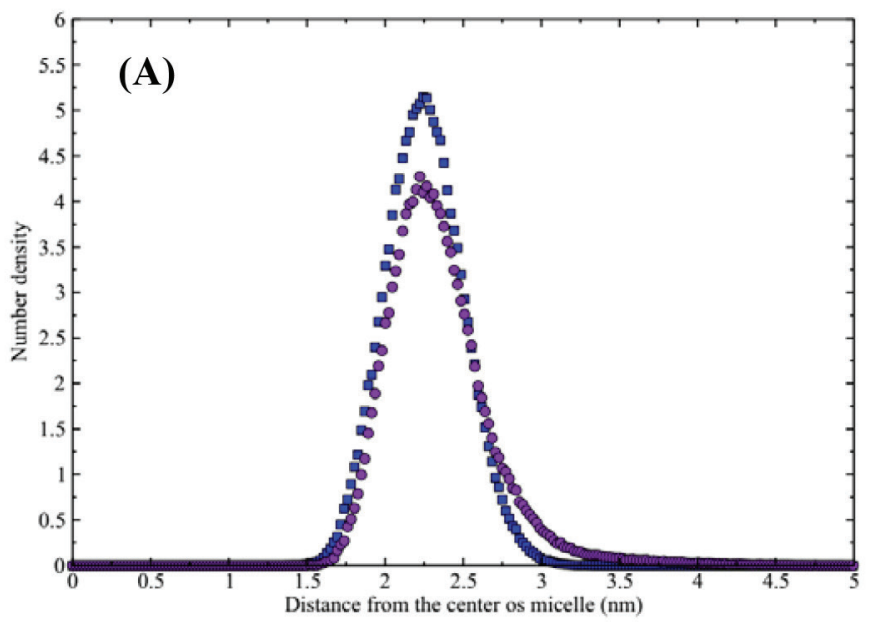

(B)

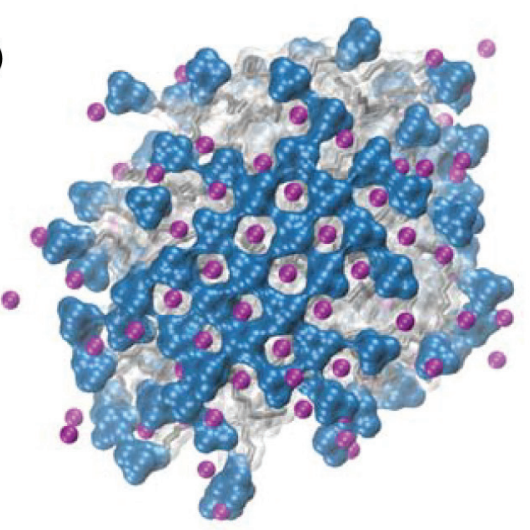

Figure 4. (A) Plot of the radial distributions (densities) of $\mathrm{N}$ (blue squares) and $\mathrm{Br}$ (magenta circles) elements for $\mathrm{CTAB}_{\mathrm{N}}$ micelles. The radial distributions of the $\mathrm{N}$ and $\mathrm{Br}$ elements yield values of 2.24 and $2.25 \mathrm{~nm}$, respectively, for the micelle radius; (B) snapshot from the MD simulation. The blue moiety and the purple spheres represent the polar head and the bromide ions, respectively. The gray lines are the apolar tails. The water molecules are not shown to facilitate visualization. 

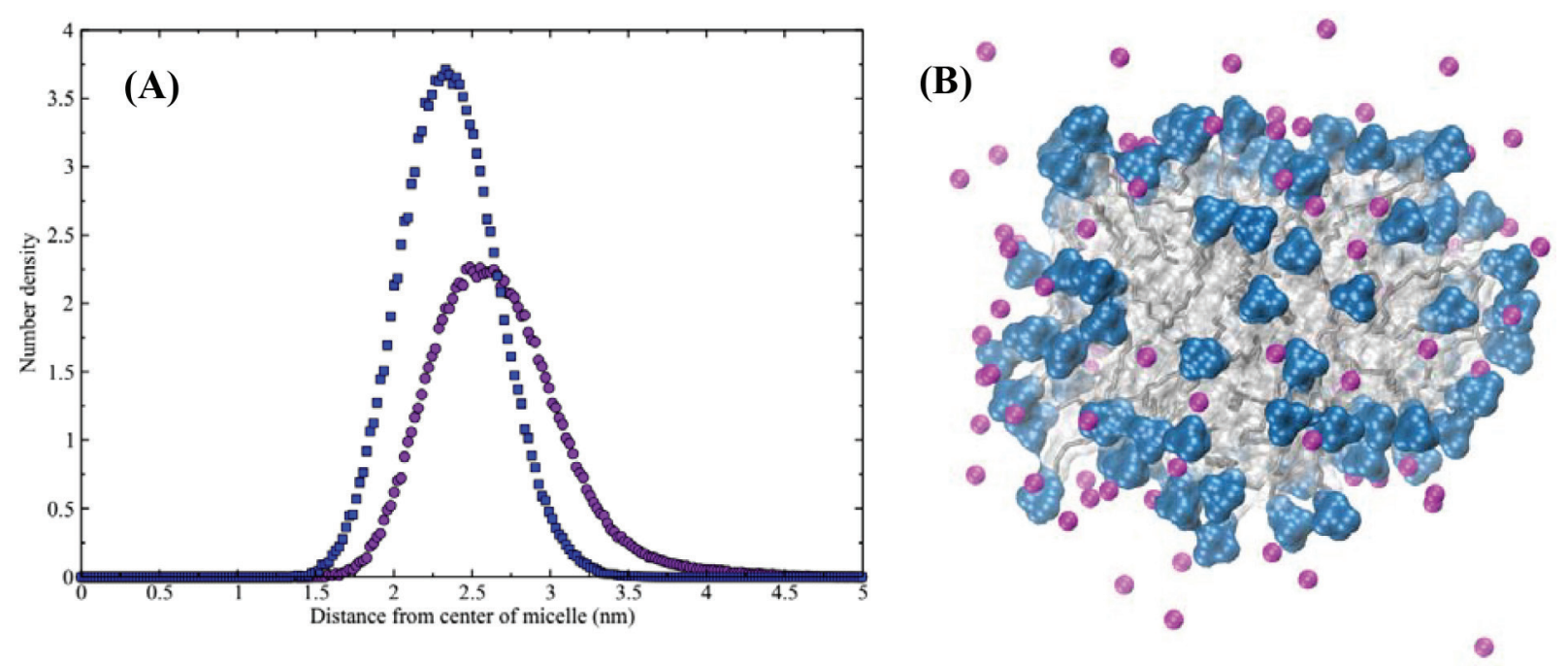

Figure 5. (A) Plot of the radial distributions (densities) of $\mathrm{N}$ (blue squares) and $\mathrm{Br}$ (magenta circles) elements for $\mathrm{CTAB}_{\mathrm{H}}$ micelles. The radial distributions of the $\mathrm{N}$ and $\mathrm{Br}$ elements yield values of 2.33 and $2.55 \mathrm{~nm}$, respectively, for the micelle radius; (B) snapshot from the MD simulation. The blue moiety and the purple spheres represent the polar head and the bromide ions, respectively. The gray lines are the apolar tails. The water molecules are not shown to facilitate visualization.
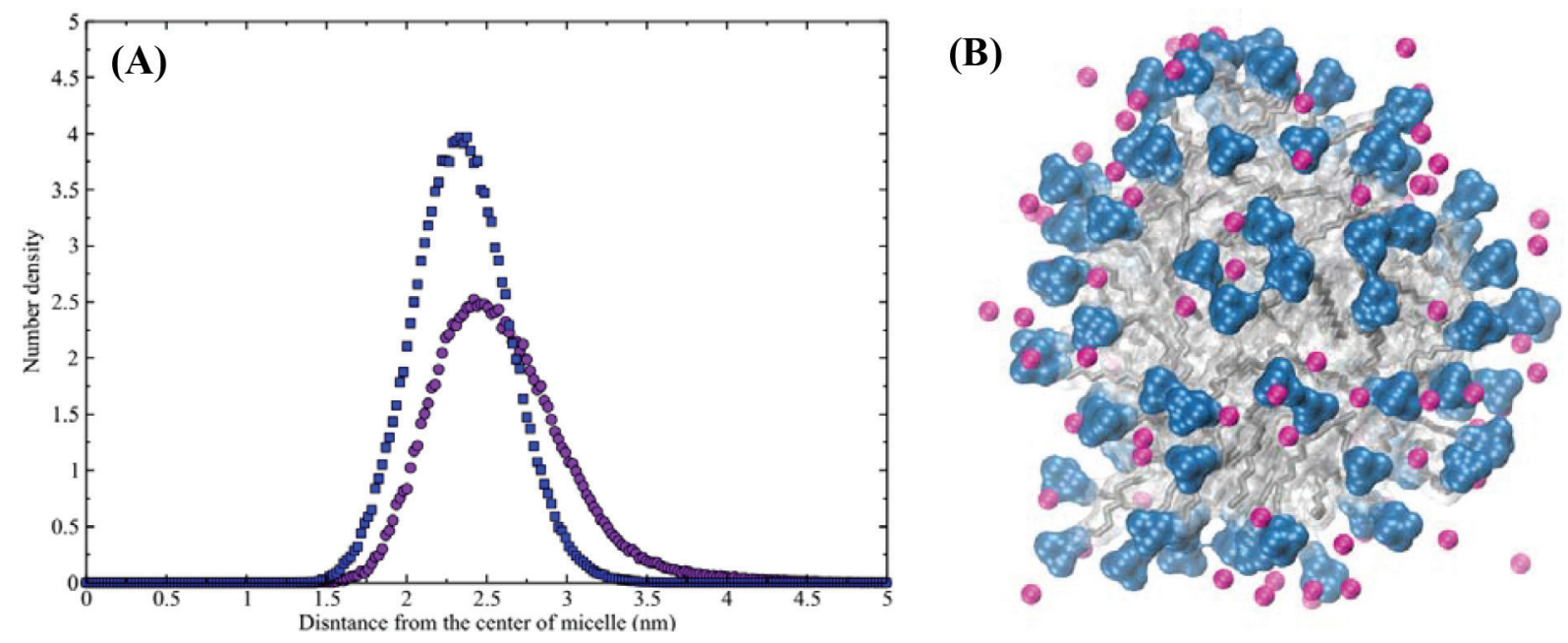

Figure 6. (A) Plot of the radial distributions (densities) of $\mathrm{N}$ (blue squares) and $\mathrm{Br}$ (magenta circles) elements for $\mathrm{CTAB}_{\mathrm{R}}$ micelles. The radial distributions of the $\mathrm{N}$ and $\mathrm{Br}$ elements yield values of 2.33 and $2.42 \mathrm{~nm}$, respectively, for the micelle radius; (B) snapshot from the MD simulation. The blue moiety and the purple spheres represent the polar head and the bromide ions, respectively. The gray lines are the apolar tails. The water molecules are not shown to facilitate visualization.

beyond the initial bilayer configuration (see Figure 4). For this reason, the $\mathrm{CTAB}_{\mathrm{N}}$ micelle model was rejected as an archetype for our simulation studies.

The $\mathrm{CTAB}_{\mathrm{H}}, \mathrm{CTAB}_{\mathrm{R}}$, and CTAC models were able to generate spherical (or globular) micellar structures in aqueous solution. Moreover, their radius values are comparable to those obtained from experimental data, ${ }^{47}$ and to the expected maximum-extension value for the $\mathrm{CTA}^{+}$ ion (ca. $2.30 \mathrm{~nm}$ ), ${ }^{20}$ even when different counterions were employed (i.e., $\mathrm{Cl}^{-}$and $\mathrm{Br}^{-}$). Despite the suitability of the data, a match between the theoretical and experimental values of the micellar radius cannot be used as the sole criterion to choose the best theoretical model. ${ }^{31}$ In this case, counterion dissociation is another parameter that must be analyzed.

The counterion dissociation degree $(\alpha)$ provides a quantitative description of the interaction between the counterions and the micellar surface. The $\alpha$ value can be estimated by the mean number of bond counterions $\left(\mathrm{n}_{\text {binding }}\right)$ of the surfactant polar group relative to the total number of positive charges, which is equivalent to $\mathrm{N}_{\mathrm{agg}}$ of the micelle. Thus, $\alpha$ can be formulated as equation $2:{ }^{49}$

$\alpha=1-\left(\frac{\mathrm{n}_{\text {binding }}}{\mathrm{N}_{\mathrm{agg}}}\right)$ 

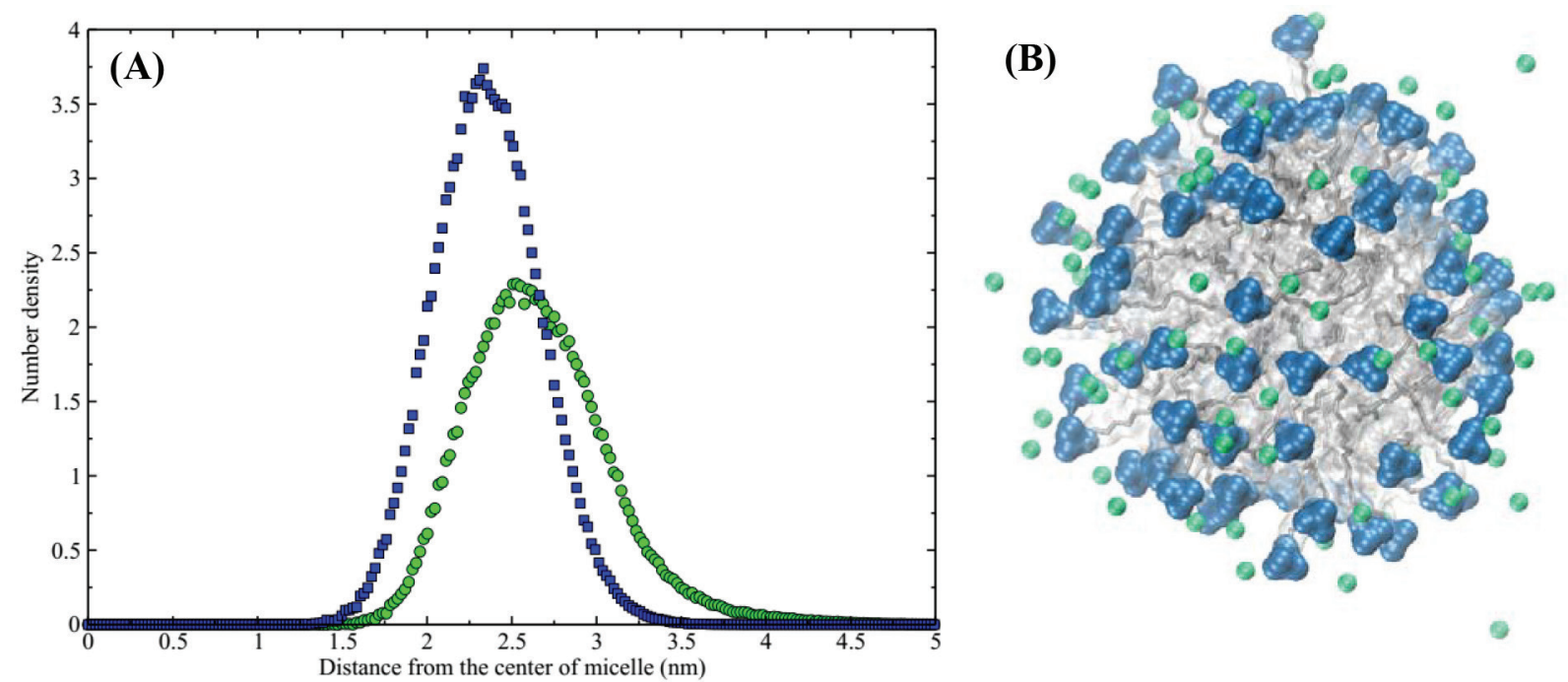

Figure 7. (A) Plot of the radial distributions (densities) of $\mathrm{N}$ (blue squares) and $\mathrm{Cl}$ (green circles) elements for CTAC micelles. The radial distributions of the $\mathrm{N}$ and $\mathrm{Cl}$ elements yield values of 2.33 and $2.55 \mathrm{~nm}$, respectively, for the micelle; (B) snapshot from the MD simulation. The blue moiety and the green spheres represent the polar head and the chloride ions. The gray lines are the apolar tails. The water molecules are not shown to facilitate visualization.

Table 2. The average radii of the micelles $\left(\mathrm{N}_{\mathrm{agg}}\right.$ of 90) simulated in this work. The radii were determined based on the highest-density areas of $\mathrm{N}$ and $\mathrm{Br}$ atoms

\begin{tabular}{lcc}
\hline Micelle model & N-micelle radius / nm & Br-micelle radius / nm \\
\hline $\mathrm{CTAB}_{\mathrm{N}}$ & 2.24 & 2.25 \\
$\mathrm{CTAB}_{\mathrm{H}}$ & 2.33 & 2.55 \\
$\mathrm{CTAB}_{\mathrm{R}}$ & 2.33 & 2.42 \\
$\mathrm{CTAC}$ & 2.33 & 2.55 \\
\hline
\end{tabular}

The criterion adopted to decide if the halide interacts with the cationic amino group is based on the distance between them. According to Wang and Larson, ${ }^{33}$ for CTAB, the distance between $\mathrm{N}^{+}$and $\mathrm{Br}^{-}$must be less than or equal to $0.68 \mathrm{~nm}$ for the two ions to be considered to have a bonding interaction. The average values for $\mathrm{n}_{\text {binding }}$ and $\alpha$ are presented in Table 3. The plots of these measurements for the last $50 \mathrm{~ns}$ are presented in the Supplementay Information (Figures S3-S6).

Table 3. Data for the average number of bonded counterions ( $\left.\mathrm{n}_{\text {binding }}\right)$ and the degree of counterion dissociation $(\alpha)$

\begin{tabular}{lcc}
\hline Model & $n_{\text {binding }}$ & $\alpha$ \\
\hline $\mathrm{CTAB}_{\mathrm{N}}$ & 81.98 & 0.08 \\
$\mathrm{CTAB}_{\mathrm{H}}$ & 59.92 & 0.33 \\
$\mathrm{CTAB}_{\mathrm{R}}$ & 67.47 & 0.25 \\
\hline
\end{tabular}

The $\alpha$ value for CTAB has been experimentally determined by several techniques, such as electrophoretic mobility $(\alpha=0.24),{ }^{50}$ conductivity $(\alpha=0.22),{ }^{50}$ rate of deprotonation of benzimidazole in CTAB-NaBr mixtures $(\alpha=0.25),{ }^{51}$ dynamic light scattering $(\alpha=0.22),{ }^{52} \mathrm{Krafft}$ temperature $(\alpha=0.25),{ }^{26}$ and chemical trapping of free counterions $(\alpha=0.25) .{ }^{53}$ By comparing the $\alpha$ values from our simulations with the experimentally obtained values, we can verify that the $\mathrm{CTAB}_{\mathrm{N}}$ and $\mathrm{CTAB}_{\mathrm{H}}$ models are inappropriate, as their $\alpha$ values are too low and too high, respectively, compared to the experimentally determined values. However, the $\alpha$ value of 0.25 obtained with the $\mathrm{CTAB}_{\mathrm{R}}$ model is quite satisfactory and matches several experimental results.

In terms of ion-water interaction for the three bromide models, the measurement of the position of the first maximum radial distribution function of water around the ion $\left(r_{\max , 1}\right)$ and hydration number in the first hydration shell around $\left(\mathrm{n}_{\mathrm{h}, \mathrm{O}}\right)$, under similar conditions, is respectively, $3.4 \AA$ and 6.5 for $\mathrm{B}_{\mathrm{H}},{ }^{34} 3.3 \AA$ and 6.0 for $\mathrm{B}_{\mathrm{N}},{ }^{35}$ and $3.5 \AA$ and 7.6 for $\mathrm{B}_{\mathrm{R}} \cdot{ }^{36}$ In this perspective, the bromide $\mathrm{B}_{\mathrm{N}}$, with a relatively small hydration layer, should display a stronger interaction with the $\mathrm{CTA}^{+}$polar group. This must be the reason the $\mathrm{CTAB}_{\mathrm{N}}$ does not evolve to the expected micellar form. Thus, according to all simulation results, the $\mathrm{CTAB}_{\mathrm{R}}$ model was selected as the best template for representing CTAB behavior in aqueous solution and is used in further studies.

\section{Simulation of $\mathrm{CTAB}_{\mathrm{R}}$ adsorption on a gold surface}

To determine whether our best CTAB-micellar model in aqueous solution $\left(\mathrm{CTAB}_{\mathrm{R}}\right)$ also demonstrates suitable behaviors under interface interactions, we carried out MD simulations of a system containing CTAB units and a gold surface in water. As already discussed, it is well known that CTAB acts as a growth-driving agent during the formation 
of gold nanorods in water, and not just as a mere stabilizing agent to prevent particle agglomeration. ${ }^{54}$ In general, it is accepted that the CTAB adsorption process on a gold surface occurs via the strong gold-bromide interactions. ${ }^{55}$

Our simulation of the adsorption of $\mathrm{CTAB}_{\mathrm{R}}$ micelles on gold surfaces shows a pattern of adjacent cylindrical micelles anchored on gold (see Figure 8). This same trend was already reported by Meena and Sulpizi. ${ }^{31,38}$ However, we have also verified the occurrence of significant interactions between the $\mathrm{CTA}^{+}$tail and the gold surface. Thus, we measured the densities of nitrogen, the last carbon of the hydrophobic tail, bromide, and water along the axis perpendicular to the surface (estimated for the last $10 \mathrm{~ns}$ of simulation); these results are presented in Figure 9.

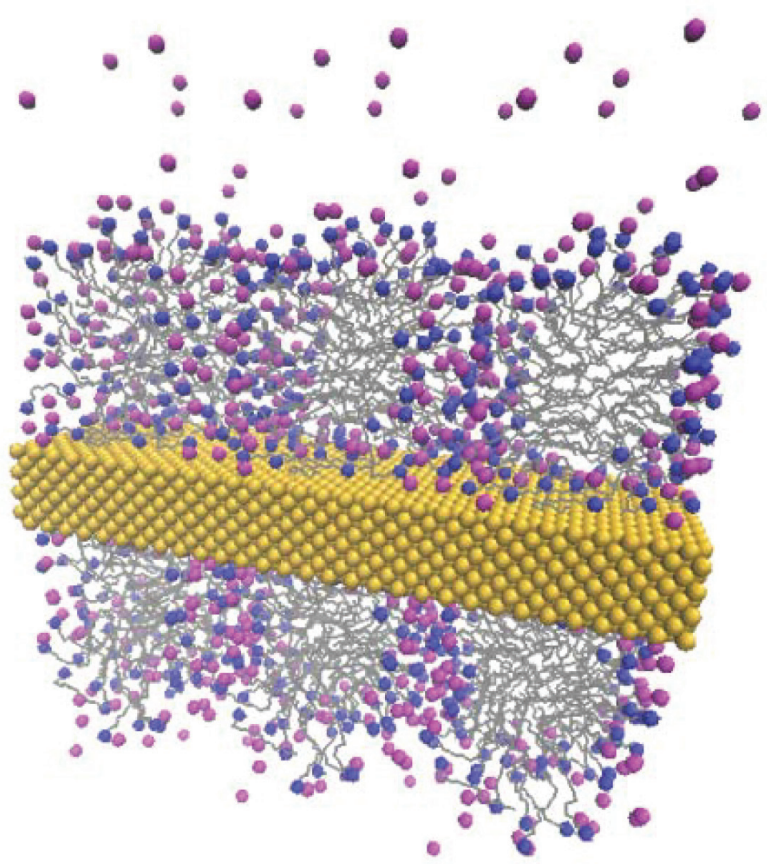

Figure 8. Snapshot of the MD simulation of $\mathrm{CTAB}_{\mathrm{R}}$ adsorption on a $\mathrm{Au}(100)$ surface. The yellow and dark-blue spheres represent gold and nitrogen atoms, respectively. The gray lines are the apolar tails. The bromide ions are represented as magenta spheres.

From Figure 9, one can observe the presence of intramicellar channels due to the distribution of nitrogen atoms along the entire length of the adsorbed layer on the surface, though the presence of nitrogen is predominant within the $0.5 \mathrm{~nm}$ distance from the surface. The distance between the two maximum nitrogen peaks can be used to estimate the thickness of the adsorbed surfactant layer; this estimated value was $3.43 \mathrm{~nm}$, which is above the value of CTAB thickness experimentally measured on the surface of gold nanorods. According to SANS studies, ${ }^{56}$ the thickness is approximately $3.2 \mathrm{~nm}$, which indicates the existence of a different adsorption-layer structure.

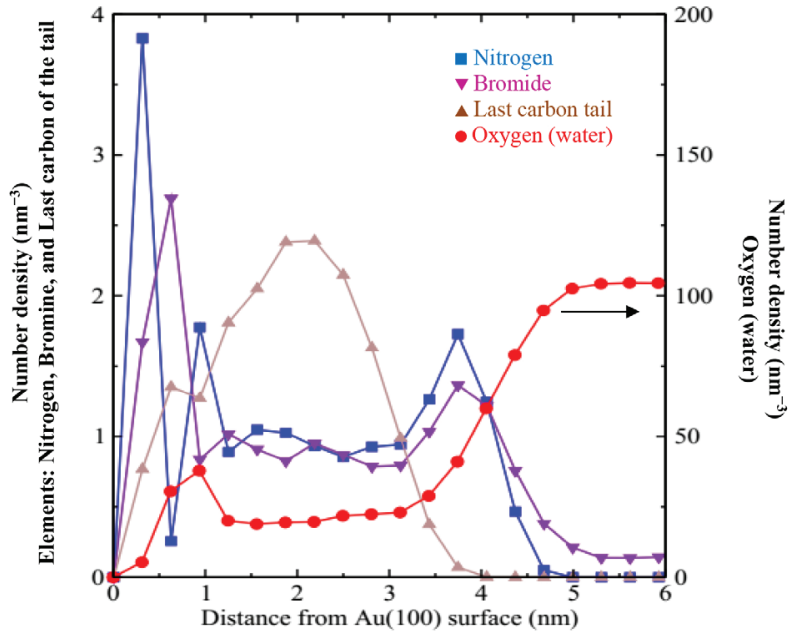

Figure 9. Measurements of the densities of nitrogen (blue square), the last carbon of the hydrophobic tail (gray triangle), bromide (magenta inverted triangle), and water molecules (red circle) in relation to the gold surface.

Our CTAB-gold adsorption simulation shows that some of the bromide ions seem to migrate through the water channels and adsorb on the gold surface, resulting in a density of 1.7 bromide ions per $\mathrm{nm}^{2}$, which is a higher value than that found by Sulpizi and co-workers ${ }^{48}$ (1.4 bromide ions per $\mathrm{nm}^{2}$ ).

The consequence of the presence of these channels is associated with the anisotropic growth mechanism of gold nanoparticles. ${ }^{31,38}$ In our study, it is interesting to note that at $0.5 \mathrm{~nm}$ from the surface, a very dense peak appears for the last carbon of the $\mathrm{CTA}^{+}$chain, which represents a constant trend of carbon-tail adsorption on the gold surface. This interaction has already been experimentally detected by Lee et al. ${ }^{57}$ and is associated with the adsorbed structure, on a gold-nanoparticle surface, at 0.5 to $2.0 \mathrm{mM}$ CTAB. Here, it is important to mention that this range of CTAB concentration is considered quite low for achieving the formation of gold nanorods. This explain why gold nanorods cannot form under low CTAB concentrations, as a compact layer of CTAB micelles cannot form on the surface of gold.

\section{Conclusions}

We believe that the results obtained with our MD simulations shed more light on the micellar structure of CTAB in solution and on the adsorption of the species on surfaces. In this work, we demonstrated that the selection of suitable parameters is quite important for producing a micellar structure in solution and modeling its interactions with other interfaces. The comparison of simulation data with data obtained experimentally demonstrated the great influence of the choice of counterion parameters on the 
formation and properties of the CTAB model. It was possible to show that the $\mathrm{CTAB}_{\mathrm{R}}$ model is capable of reproducing various experimental properties and is a promising candidate for use in many situations involving micellar structures in solution or adsorbed on a gold surface. The micellar radius $(2.33 \mathrm{~nm})$ and counterion dissociation degree $(\alpha=0.25)$ are consistent with experimental data. The $\mathrm{CTAB}_{\mathrm{R}}$ model also demonstrates specific interface interactions, such as CTAB-gold surface interactions. The thickness of the adsorbed surfactant layer, which is composed of cylindrical micelles, is approximately $3.43 \mathrm{~nm}$ (if they were spherical, the thickness would be approximately $4.66 \mathrm{~nm})$. Relatively few bromide ions are adsorbed on the gold surface $\left(1.7 \mathrm{~nm}^{-2}\right)$; however, they appear throughout the length of the channels, solvated by water molecules present in the channels. A very dense peak appears $0.5 \mathrm{~nm}$ from the surface for the last carbon of the CTAB chain, which represents a constant trend of carbon-tail adsorption on the gold surface. This specific CTAB chain-gold interaction was already detected experimentally by Lee et $a l .{ }^{57}$ at low CTAB concentrations, through which stable micelles can be formed on the gold surface.

\section{Supplementary Information}

Supplementary information (molecular structures of CTAB and DPPC lipid; charges of the CTAB carbon and nitrogen atoms; and the graphical representation of $\alpha$ ) is available free of charge at http://jbcs.sbq.org.br as PDF file.

\section{Acknowledgments}

The authors acknowledge Marialore Sulpizi at Johannes Gutenberg University, Germany, for kindly making available the atomic coordinates for the gold surfaces. The authors are grateful to the Brazilian Funding agencies (CNPq, Capes, Fapeal, INCT-Catalise, Facepe and CapesBioMol) for financial support and for the computational resources provided by the Cenapad-Unicamp. M. R. M. thanks CNPq for the research fellowships.

\section{References}

1. Rosen, M. J.; Kunjappu, J. T.; Surfactants and Interfacial Phenomena, $4^{\text {th }}$ ed.; John Wiley \& Sons: Hoboken, New Jersey, USA, 2012.

2. Jonsson, B.; Lindman, B.; Holmberg, K.; Kronberg, B.; Surfactants and Polymers in Aqueous Solution, $4^{\text {th }}$ ed.; John Wiley \& Sons: New York, USA, 1998.

3. Castro, M. J. L.; Ojeda, C.; Cirelli, A. F.; Environ. Chem. Lett. 2014, 12,85 .
4. Bakshi, M. S.; Cryst. Growth Des. 2016, 16, 1104.

5. Roy, J. C.; Islam, M. N.; Aktaruzzaman, G.; J. Surfactants Deterg. 2014, 17, 231.

6. Nagarajan, R.; Esumi, K.; Ueno, M.; Theory of Micelle Formation: Quantitative Approach to Predicting Micellar Properties from Surfactant Molecular Structure, $2^{\text {nd }}$ ed.; Marcel Dekker: New York, USA, 2003.

7. Iyer, J.; Blankschtein, D.; J. Phys. Chem. B 2012, 116, 6443.

8. Verma, G.; Aswal, V. K.; Kulshreshtha, S. K.; Hassan, P. A.; Kaler, E. W.; Langmuir 2008, 24, 683.

9. Bratt, P. J.; Gillies, D. G.; Sutcliffe, L. H.; Williamst, A. J.; J. Phys. Chem. 1990, 94, 2727.

10. Bockstaele, M. V.; Gelan, J.; Martens, H.; Put, J.; Schryver, F. C. D.; Dederen, J. C.; Chem. Phys. Lett. 1980, 70, 605.

11. Zettl, H.; Portnoy, Y.; Gottlieb, M.; Krausch, G.; J. Phys. Chem. B 2005, 109, 13397.

12. Sharma, V. K.; Mitra, S.; Verma, G.; Hassan, P. A.; Sakai, V. G.; Mukhopadhyay, R.; J. Phys. Chem. B 2010, 114, 17049.

13. Sharma, V. K.; Mitra, S.; Sakai, V. G.; Mukhopadhyay, R.; J. Phys. Chem. B 2012, 116, 9007; Sharma, V. K.; Mitra, S.; Johnson, M.; Mukhopadhyay, R.; J. Phys. Chem. B 2013, 117, 6250.

14. Michaux, F.; Blin, J.; Teixeira, J.; Stébé. M. J.; J. Phys. Chem. B 2012, 116, 261.

15. Gapiński, J.; Szymański, J.; Wilk, A.; Kohlbrecher, J.; Patkowski, A.; Hołyst, R.; Langmuir 2010, 26, 9304.

16. Manet, S.; Cuvier, A.; Valotteau, C.; Fadda, G. C.; Perez, J.; Karakas, E.; Abel, S.; Baccile, N.; J. Phys. Chem. B 2015, 119, 13113.

17. Lizhong; Garamus, V. M.; Funari, S. S.; Malfois, M.; Willumeit, R.; Niemeyer, B.; J. Phys. Chem. B 2002, 106, 7596.

18. Marrink, S. J.; Tieleman, D. P.; Mark, A. E.; J. Phys. Chem. B 2000, 104, 12165; Mohan, G.; Kopelevich, D. I.; J. Chem. Phys. 2008, 128, 44905; Volkov, N. A.; Divinskiy, B. B.; VorontsovVelyaminov, P. N.; Shchekin, A. K.; Colloids Surf., A 2015, 480, 165; Mackereel Jr., A. D.; J. Phys. Chem. 1995, 99, 1846; Bruce, C. D.; Berkowitz, M. L.; Perera, L.; Forbes, M. D. E.; J. Phys. Chem. B 2002, 106, 3788; Palazzesi, F.; Calvaresi, M.; Zerbetto, F.; Soft Matter 2011, 7, 9148; Sammalkorpi, M.; Karttunen, M.; Haataja, M.; J. Phys. Chem. B 2007, 111, 11722; Bogusz, S.; Venable, R. M.; Pastor, R. W.; J. Phys. Chem. B 2001, 105, 8312.

19. Tanford, C.; J. Phys. Chem. 1972, 76, 3020.

20. Speranza, F.; Pilkington, G. A.; Dane, T. G.; Cresswell, P. T.; Li, P.; Jacobs, R. M. J.; Arnold, T.; Bouchenoire, L.; Thomas, R. K.; Briscoe, W. H.; Soft Matter 2013, 9, 7028.

21. Dvoracek, C. M.; Sukhonosova, G.; Benedikand, M. J.; Grunlan, J. G.; Langmuir 2009, 25, 10322.

22. Xu, L.; Feng, L.; Hao, J.; Dong, S.; ACS Appl. Mater. Interfaces 2015, 7, 8876; Cheng, W.; Dong, S.; Wang, E.; Langmuir 2003, 19, 9434; Silva, M. G. A.; Nunes, A. M.; Meneghetti, S. M. P.; Meneghetti, M. R.; C. R. Chim. 2013, 16, 640. 
23. Murphy, C.; Sau, T.; Gole, A.; Orendorff, C.; Gao, J.; Gou, L.; Hunyadi, S.; Li, T.; J. Phys. Chem. B 2005, 109, 13857; Murphy, C. J.; Thompson, L. B.; Chernak, D. J.; Yang, J. A.; Sivapalan, S. T.; Boulos, S. P.; Huang, J.; Alkilany, A. M.; Sisco, P. N.; Curr. Opin. Colloid Interface Sci. 2011, 16, 128; Nikoobakht, B.; El-Sayed, M. A.; Chem. Mater. 2003, 15, 1957.

24. Goyal, P. S.; Dasannacharya, B. A.; Kelkar, V. K.; Manohar, C.; Rao, S.; Valaulikar, B. S.; Phys. B (Amsterdam, Neth.) 1991, 174, 196.

25. Ekwall, P.; Mandell, L.; Solyom, P.; J. Colloid Interface Sci. 1971, 35, 519

26. Vautier-Giongo, C.; Bales, B. L.; J. Phys. Chem. B 2003, 107, 5398.

27. Bergström, L. M.; J. Colloid Interface Sci. 2015, 440, 109.

28. Bergström, L. M.; Curr. Opin. Colloid Interface Sci. 2016, 22, 46.

29. Reiss-Husson, F.; Luzzati, V.; J. Phys. Chem. 1964, 68, 3504.

30. Cata, G. F.; Rojas, H. C.; Gramatges, A. P.; Zi-covich-Wilson, C. M.; Alvarez, L. J.; Searle, C.; Soft Matter 2011, 7, 8508.

31. Meena, S. K.; Sulpizi, M.; Langmuir 2013, 29, 14954.

32. Schmid, N.; Eichenberger, A. P.; Choutko, A.; Riniker, S.; Winger, M.; Mark, A. E.; van Gunsteren, W. F.; Eur. Biophys. J. 2011, 40, 843.

33. Wang, Z.; Larson, R. G.; J. Phys. Chem. B 2009, 113, 13697.

34. Deublein, S.; Vrabec, J.; Hasse, H.; J. Chem. Phys. 2012, 136, 501.

35. Mamatkulov, S.; Fyta, M.; Netz, R. R.; J. Chem. Phys. 2013, 138, 505.

36. Reiser, S.; Deublein, S.; Vrabec, J.; Hasse, H.; J. Chem. Phys. 2014, 140, 504 .

37. Heinz, H.; Vaia, R. A.; Farmer, B. L.; Naik, R. R.; J. Phys. Chem. C 2008, 112, 17281.

38. Meena, S. K.; Sulpizi, M.; Angew. Chem., Int. Ed. 2016, 55, 11960.

39. Bergstrom, L. M.; Grillo, I.; Soft Matter 2014, 10, 9362.

40. Aswal, V. K.; Goyal, P. S.; Chem. Phys. Lett. 2003, 368, 59; Törnblom, M.; Henriksson, U.; Ginley, M.; J. Phys. Chem. 1994, 98, 7041
41. Berendsen, H. J. C.; Grigera, J. R.; Straatsma, T. P.; J. Phys. Chem. 1987, 91, 6269.

42. Berendsen, H. J. C.; Postma, J. P. M.; van Gunsteren, W. F.; DiNola, A.; Haak, J. R.; J. Chem. Phys. 1984, 81, 3684.

43. Parrinello, M.; Rahman, A.; J. Appl. Phys. 1981, 52, 7182.

44. Tironi, I. G.; Sperb, R.; Smith, P. E.; van Gunsteren, W. F.; J. Chem. Phys. 1995, 102, 5451.

45. Spoel, D. V. D.; Lindahl, E.; Hess, B.; Groenhof, G.; Mark, A. E.; Berendsen, H. J. C.; J. Comput. Chem. 2005, 26, 1701.

46. Humphrey, W.; Dalke, A.; Schulten, K.; J. Mol. Graphics 1996, $14,33$.

47. Imae, T.; Kamiya, R.; Ikeda, S.; J. Colloid Interface Sci. 1985, $108,215$.

48. Meena, S. K.; Schäfer, S. C. P.; Henkel, A.; Sönnichsen, C.; Sulpizi, M.; Phys. Chem. Chem. Phys. 2016, 18, 13246.

49. Bales, B. L.; J. Phys. Chem. B 2001, 105, 6798.

50. Sepulveda, L.; Cortes, J.; J. Phys. Chem. 1985, 89, 5322.

51. Bunton, C. A.; Romsted, L. S.; Sepulveda, L.; J. Phys. Chem. 1980, 84, 2611.

52. Dorshow, R.; Briggs, J.; Bunton, C. A.; Nicoli, D. F.; J. Phys. Chem. 1982, 86, 2388.

53. Cuccovia, I. M.; da Silva, I. N.; Chaimovich, H.; Langmuir 1997, 13, 647.

54. Li, N.; Zhao, P.; Astruc, D.; Angew. Chem., Int. Ed. 2014, 53, 1756.

55. Ha, T. H.; Koo, H. J.; Chung, B. H.; J. Phys. Chem. C 2007, $111,1123$.

56. Gómez-Graña, S.; Hubert, F.; Testard, F.; Guerrero-Martínez, A.; Grillo, I.; Liz-Marzán, L. M.; Spalla, O.; Langmuir 2012, $28,1453$.

57. Lee, S.; Anderson, L. J. E.; Payne, C. M.; Hafner, J. H.; Langmuir 2011, 27, 14748 .

Submitted: May 2, 2017

Published online: July 7, 2017 